\title{
MICROGRAVITY SUPERAGGLOMERATES PRODUCED BY SILANE AND ACETYLENE
}

\author{
Matthew Bundy, George W. Mulholland, Samuel Manzello, Jiann Yang, John Henry Scott \\ National Institute of Standards and Technology, Gaithersburg, MD, 20899 \\ Yudaya Sivathanu \\ En’Urga, Inc., West Lafayette, IN 47906.
}

\section{Introduction}

The size of the agglomerates produced in the in the upper portion of a flame is important for a variety of applications. Soot particle size and density effect the amount of radiative heat transfer from a fire to its surroundings. Particle size determines the lifetime of smoke in a building or in the atmosphere, and exposure hazard for smoke inhaled and deposited in the lungs. The visibility through a smoke layer and dectectability of the smoke are also greatly affected by agglomerate size. Currently there is limited understanding of soot growth with an overall dimension of $10 \mu \mathrm{m}$ and larger. In the case of polystyrene, smoke agglomerates in excess of 1 $\mathrm{mm}$ have been observed "raining" out from large fires.

Unlike hydrocarbon fuels, silane has the advantage that silica particles are the major combustion product resulting in a particle volume fraction a factor of ten greater than that for a carbonaceous smoke. There are two very desirable properties of silica aero-gels that are important for both space and earth based applications. The first important property is its inertness to most oxidizing and reducing atmospheres. Therefore, silica aero-gels make excellent fire ablatives and can be used in very demanding applications. The second important property is that silica aero-gels are expected to have very high porosity (greater than 0.999), making them lightweight and ideal for aerospace applications. The added benefit of the high porosity is that they can be used as extremely efficient filters for many earth based applications as well.

Evidence of the formation of superagglomerates in a laminar acetylene/air diffusion flame was found by Sorensen et al. [1]. An interconnecting web of super-agglomerates was observed to span the width of the soot plume in the region just above the flame tip and described as a gel state. It was observed that this gel state immediately breaks up into agglomerates as larges as $100 \mu \mathrm{m}$ due to buoyancy induced turbulence. Large soot agglomerates were observed in microgravity butane jet diffusion flames by Ito et al.[2]. Several other works to date have studied the effect of flame structure on soot volume fraction and agglomeration size in a microgravity environment.[3-4]. In microgravity the absence of buoyant convective flows increases the residence time in the flame and causes a broadening of the high temperature region in the flame. Both of these factors play a significant role in gas phase radiation and soot formation

\section{Experimental Hardware}

Experiments were performed using a combustion "drop rig" that was designed for use at NASA Glenn's 2.2 second drop tower facility. The hardware consisted of a $25 \mathrm{~L}$ combustion chamber, an open tube burner, a gas flow control system, an electrical system and an imaging 
system. The burner consisted of a $4.52 \mathrm{~mm}$ diameter stainless steel tube positioned along the centerline $15 \mathrm{~cm}$ above the base of the chamber. Two CCD video cameras were used to image the flame and soot plume. Illumination for imaging the agglomerates was provided using a microsecond Xenon flashlamp. A $0.25 \mathrm{~mm}$ diameter Kanthol hot-wire was used to ignite the flame. Pressure transducers were used to monitor the fuel bottle and combustion chamber pressure. Rotary solenoids were used to position the ignition wire and TEM sampling grid.

\section{Normal Gravity Experiments}

Acetylene and silane was burned in the standard NASA cylindrical combustion chamber. A digital camera with backlighting through a diffuser was used to photograph both the flame and smoke plume as illustrated in the lower portions of the Figure 1. The photographs show the

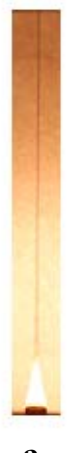

a

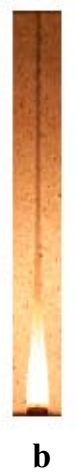

b

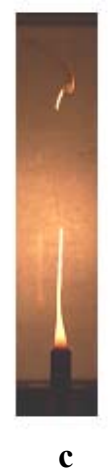

c

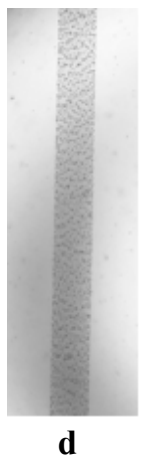

d

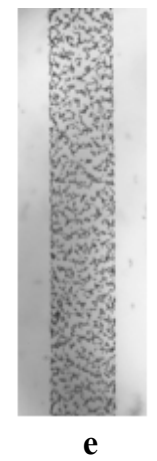

e

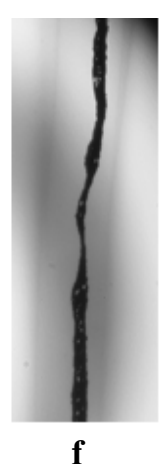

Figure 1. Photograph of acetylene and silane flames in normal gravity.

flame and plume for an acetylene fuel flow rate of $0.66 \mathrm{~cm}^{3} / \mathrm{s}, 2.10 \mathrm{~cm}^{3} / \mathrm{s}$, and for a silane flow rate of $2.1 \mathrm{~cm}^{3} / \mathrm{s}$ ( $\mathrm{a}, \mathrm{b}$ and $\mathrm{c}$ respectively). The series of photographs (d, e, and $\mathrm{f}$ ) in Fig. 2 were taken at a location about $9 \mathrm{~cm}$ from the burner exit with the digital camera and a Xenon flash lamp with a pulse duration of $1.3 \mu$ s and a pulse energy of $0.35 \mathrm{~J}$ to "freeze" the motion of the soot agglomerates. At the lower flow rate the soot appears as a relatively gray background while at the larger flow, individual $50 \mu \mathrm{m}$ to $100 \mu \mathrm{m}$ particles appear to be connected across much of the plume. Other noteworthy features are the increasing plume width with increasing fuel flow rate and the sharpness of the smoke boundary. For the silane flames, filaments were observed leaving the flame zone rather than superagglomerates such as for acetylene. A $\mu$ s flash photograph of a filament $9 \mathrm{~cm}$ above the flame is shown in Fig. 1c.

Fibrous particles were examined with a stereomicroscope (Fig 2a) and a field emission scanning electron microscope (Fig. 2b). The SEM micrograph shows evidence of partially fused spherule structures with diameters as small as $150 \mathrm{~nm}$. We expected that the much larger particulate volume fraction for the silane flame would lead to a totally interconnected gel-like structure and were surprised to observe a fibrous material. It is likely that the combination of the higher flame temperature for silane combustion together with the lower melting point of $\mathrm{SiO}_{2}$ particulate has resulted in the formation of the partially fused filaments. An interesting hollow cage-like structure, shown in Fig. 2c was produced when the fuel line was purged with a pulse of nitrogen at the end of the experiment. This suggests that varying the flame temperature by diluting the silane will likely be important in controlling the morphology of the silane particles. 

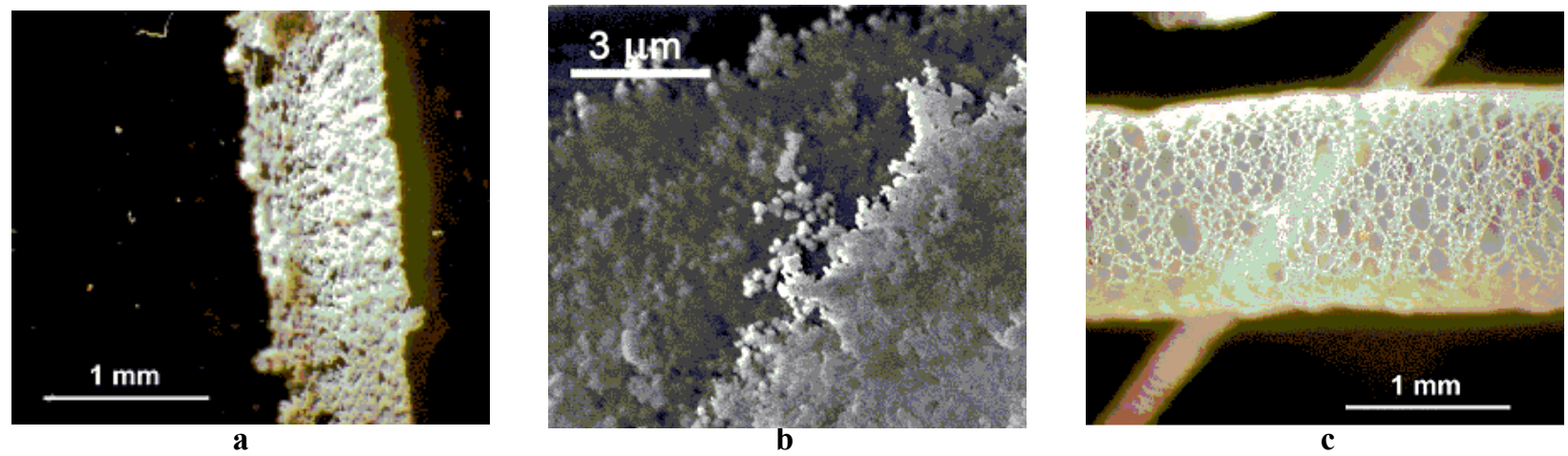

Figure. 2. Optical micrograph of silica fiber.

\section{Microgravity Acetylene Experiments}

Microgravity experiments were performed in a 2.2 second drop tower using acetylene at flow rates of $0.6 \mathrm{cc} / \mathrm{s}, 1.0 \mathrm{cc} / \mathrm{s}$ and $2.0 \mathrm{cc} / \mathrm{s}$. Fig. 3 ( $\mathrm{a}$ and b) shows images of the acetylene flames and soot plumes recorded during the microgravity experiments. The microgravity flame was three times as wide as the normal gravity flame.

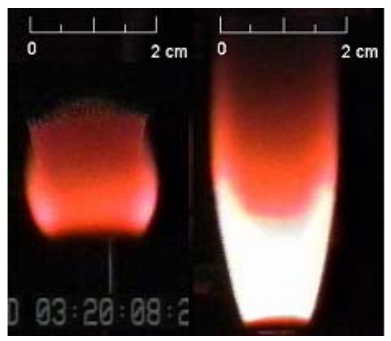

a

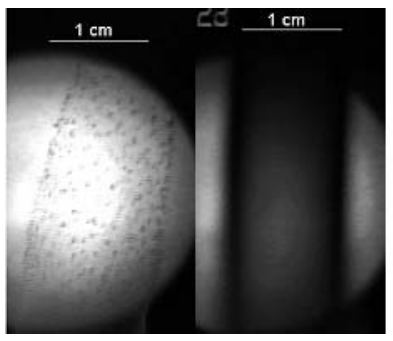

b

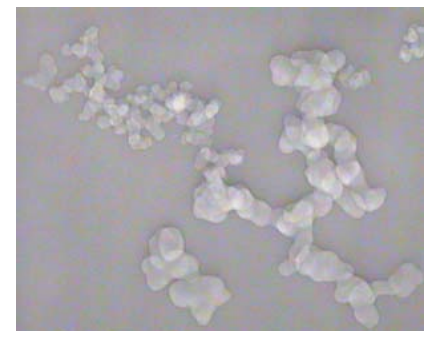

c

Figure 3. Images of acetylene flame and the soot plume and a TEM photo.

Although detailed measurements of the agglomerate size were not possible due to the low image resolution, approximate particle sizes were attained in the post flame region between 2.5 $\mathrm{cm}$ and $5.5 \mathrm{~cm}$ above the burner. Microgravity superagglomerates as large as $(1.2 \pm 200) \mathrm{mm}$ were observed in these experiments. Another noteworthy observation is apparent from inspection of the flame video in slow motion. It appears that superagglomerates can be seen escaping from the open flame tip annulus in the $\mu \mathrm{G}$ flames at acetylene flow rates of $0.6 \mathrm{cc} / \mathrm{s}$ and $1.0 \mathrm{cc} / \mathrm{s}$. This suggests that the large soot agglomerates are formed in the high temperature region of the flame. Detailed measurement of the primary particle size distribution was performed for soot sampled at three flame conditions at a location of $25 \mathrm{~mm}$ above the burner duct. At least 100 primary spheres were analyzed for each condition. The diameter of the primary particles for the $2.0 \mathrm{cc} / \mathrm{s}$ flame was measured to be $(45.4 \pm 10.2) \mathrm{nm}$ in $\mu$-g and $(40.0 \pm$ $11.4) \mathrm{nm}$ in 1-g. A digitized TEM micrographs for soot particles sampled above the $1.0 \mathrm{cc} / \mathrm{s}$ acetylene flame in microgravity is shown in Fig. 9. Inspection of this image clearly shows clusters formed from 2 different primary particle sizes measured to have diameters of $(16.3 \pm 5)$ $\mathrm{nm}$ and $(43.0 \pm 9) \mathrm{nm}$. This feature was found throughout the entire TEM grid with a slightly higher number of small particle clusters, however since only a single TEM grid was collected for this condition the nature and generality of this bimodal feature is uncertain. 


\section{Numerical Simulations}

Temperature and soot volume fraction contours for normal gravity and microgravity acetylene flames were calculated [8,9]. These results were consistent with the qualitative observations from the $\mu \mathrm{G}$ experiments. The calculations of the soot volume fraction and temperature field in the flame zone/plume together with the calculation of the particle position versus time provides the necessary input to estimate the agglomerate growth for the case of a 1 $\mathrm{cm}^{3} / \mathrm{s}$ acetylene flow rate [10]. Our agglomeration simulations suggest than free molecular coagulation together with gelation are too slow to produce superagglomerates of size greater than $100 \mu \mathrm{m}$ for 1 -g experiments. The simulations predict a relatively modest enhancement in the agglomeration as the gel point is approached for the free molecular limit. For $\mu$-g conditions, our simulation results predict a maximum agglomerate length of $35 \mu \mathrm{m}$ based on $f_{V}=6.0 \times 10^{-6}$ and a length of $680 \mu \mathrm{m}$ for $\mathrm{f}_{\mathrm{V}}=6.0 \times 10^{-4}$. For the higher density it is seen that the agglomeration model predicts that agglomerates approaching the critical gel size would form in a flame at $\mu-g$ conditions.

\section{Conclusions}

1. For the first time in $\mu$-g the emission of soot super-agglomerates from the luminous flame was visually demonstrated by simultaneously imaging the flame and soot plume.

2. The burning of silane at 1 -g results in novel structures including fibers and cage-like structures depending on the time/temperature history for the particles in the flame.

3. The flame calculations show an increased residence time in $\mu$-g which helps explain enhanced agglomerate growth.

4. A soot agglomerate model based on Brownian motion can not account for the superagglomerates observed in acetylene flames at 1-g.

\section{Acknowledgements}

This work is funded by NASA Microgravity Combustion Program with Suleyman Gokoglu as technical monitor. Paul Greenburg, David Urban, and Eric Bauman from NASA Glenn provide significant support for the drop tower experiments. Jinyu Zhu designed the silane flow system, Anthony Hamins carried out silane flame calculations, and Marco Fernandez fabricated the Super Agglomerate Drop Tower facility.

\section{References}

[1] Sorensen, C.M., Hageman, W.B., Rush, T.J., Huang, H., Oh, C., Phys. Rev. Lett., 80:1782 (1998).

[2] Ito, H., Fujita, O., Ito, K., Combustion and Flame, 99:363 (1994).

[3] Ku, J.C., Tong, L., Sun, J., Greenberg, P.S., Griffin, D.W., Proceedings of the Second International Microgravity Combustion Workshop, 121 (1992).

[4] Koylu, U.O. and Faeth, G.M., Combustion and Flame, 89:140 (1992).

[5] Sivathanu, Y.R. and Gore, J.P., Combustion and Flame, 97: 161 (1994).

[6] Leung, K.M., Lindsted, and Jones, W.P., Combustion and Flame, 87:289 (1991).

[7] Mulholland et al., Energy and Fuels, 2, 481-486 (1988). 